"This is the peer reviewed version of the following article: Peleman B, Lazzari A, Budginaite I, et al. Continuous professional development and_ECEC quality: Findings from a European systematic literature review. Eur J Educ. 2017;00:1-14 which has been published in final form at https://doi. org/10.1111/ejed.12257. This article may be used for non-commercial purposes in accordance with Wiley Terms and Conditions for Use of Self-Archived Versions. This article may not be enhanced, enriched or otherwise transformed into a derivative work, without express permission from Wiley or by statutory rights under applicable legislation. Copyright notices must not be removed, obscured or modified. The article must be linked to Wiley's version of record on Wiley Online Library and any embedding, framing or otherwise making available the article or pages thereof by third parties from platforms, services and websites other than Wiley Online Library must be prohibited." 


\title{
Continuous Professional Development and ECEC quality: Findings from a European systematic literature review
}

Brecht Peleman, Arianna Lazzari, Irma Budginaitè, Hanna Siarova, Hanan Hauari, Jan Peeters, \& Claire Cameron

\begin{abstract}
This article presents the findings of an analysis of the effects of CPD initiatives on the quality of the pedagogical practices of ECEC practitioners. It is part of a larger study commissioned by Eurofound and jointly conducted by VBJK, IOE and PPMI (Eurofound, 2015). In order to draw policy-relevant information that might support decision makers in designing effective ECEC policies in their countries, the study reviewed existing research evidence published on this topic not only in English, but also in all the languages currently in use in EU Member States. Therefore, it involved country experts from EU-28 Member States. The research question was framed by the political priorities identified by the Council Conclusions on Early Childhood Education and Care (EU Council, 2011). The systematic literature review methodology elaborated by the EPPI-Centre for informing evidence-based policies in the field of education and social sciences was adopted to review the evidence drawn from primary research studies cross-nationally. The study revealed that long-term CPD interventions integrated into practice, such as pedagogical guidance and coaching in reflection groups, proved to be effective not only in countries with a well-established system of ECEC provision and a high level of qualification requirements for the practitioners, but also in countries with poorly subsidised ECEC systems and low qualification requirements. CPD initiatives based on the active engagement of practitioners and on peer exchanges within a shared scientific framework, proved to be the most effective.
\end{abstract}

\section{KEYWORDS:}

Continuous professional development, - early childhood education and care services, European policies, pedagogical quality, systematic literature review 


\section{Continuous Professional Development and ECEC quality: Findings from a European systematic literature review}

Brecht Peleman, Arianna Lazzari, Irma Budginaitė, Hanna Siarova, Hanan Hauari, Jan Peeters, \& Claire Cameron

Correspondence

Brecht Peleman, Centre for Innovation in the Early Years, Raas Van Gavereststraat 67 A, 9000 Ghent, Ghent University, Department of Social Work and Social Pedagogy, H. Dunantlaan 2, 9000 Ghent, Belgium

Email: brecht.peleman@vbjk.be

Arianna Lazzari, University of Bologna, Via Zamboni 33, 40126 Bologna, Italy

Email: $\underline{\text { arianna.lazzari2@unibo.it }}$

Irma Budginaité, Public Policy and Management Institute, Gedimino pr 50, 01110 Vilnius, Lithuania

Email: irma@ppmi.lt

Hanna Siarova, Public Policy and Management Institute, Gedimino pr 50, 01110 Vilnius, Lithuania

Email: hanna.siarova@ppmi.lt

Hanan Hauari, Thomas Coram Research Unit, Institute of Education, University of London, Gower Street, London WC1E 6BT, UK

Email: H.Hauari@ioe.ac.uk

Jan Peeters, Centre for Innovation in the Early Years, Raas Van Gavereststraat 67 A, 9000 Ghent, Belgium

Email: jan.peteers@vbjk.be

Claire Cameron, Thomas Coram Research Unit, Institute of Education, University of London, Gower Street, London WC1E 6BT, UK

Email: $\underline{\text { C.Cameron@ioe.ac.uk }}$

\section{INTRODUCTION: THE POLICY CONTEXT}

In response to recent demographic, economic and social challenges, early childhood education and care (ECEC) has moved up the European policy agenda (European Commission, 2011). Findings from recent studies carried out in Europe concur that participation in high quality ECEC services have long lasting beneficial effects on children's overall development (Bennett, Gordon, \& Edelmann, 2012) and can make a substantial contribution towards addressing social and cultural inequalities by fostering social cohesion (Eurydice, 2009, European Commission, 2014). Despite being a world leader in providing ECEC services, international reports have identified that more efforts needed to be made to increase the quality and accessibility of provision across EU Member States (NESSE, 2009, European Commission, 2014). The purpose of education and social policies 
should be to ensure an equal and generalised access to ECEC services of high quality, facilitating a positive impact of attendance on children's learning and socialisation experiences, especially in contexts of growing socio-cultural diversity (European Commission, 2011).

In May 2011, the European Council concluded that, whilst considerable attention had been given to increasing the number of ECEC places over the last decade, generalised equitable access to high quality ECEC was now equally important if the EU 2020 benchmarks ${ }^{1}$ on reducing early school leaving and tackling poverty and social exclusion were to be met (Council of the European Union, 2011). In this regard, the Council Conclusions also mention 'supporting the professionalization of ECEC staff, with an emphasis on the development of their competencies, qualifications and working conditions, and enhancing the prestige of the profession' (Council of the European Union, 2011, p. 6) as measures to improve the quality of ECEC provision. The European Commission DG Education and Culture responded to these conclusions by setting up a Thematic Working Group on Early Childhood Education and Care in the context of the 'Strategic framework for European cooperation in education and training' (ET2020). The Thematic Working Group, consisting of a group of representatives from 26 EU Member States and of a stakeholder group, developed a European Quality Framework (EQF) on ECEC that was released at the Presidency conference in Athens in June 2014 and officially launched by the DG Education and Culture at the 'Great start in life conference' (Brussels, 30 November-1 December 2016) (https://ec.europa.eu/education/great-start-in-life_en\#documents) in 2016. The EQF consists of eight statements, two of which focus on the role played by the ECEC workforce in enhancing the pedagogical quality of services for young children and improving their outcomes. The statements encourage EU Member States to develop comprehensive training programmes for all staff employed in these services (e.g., preschool teachers, assistants, educators, family day carers) and provide supportive conditions which create opportunities for observation, reflection, planning, teamwork and cooperation with parents (Bennett \& Moss, 2011; Urban, Vandenbroeck, Peeters, Lazzari, \& Van Laere, 2011; Oberhuemer, 2012).

Beyond the EU context, high profile international organisations (e.g., OECD, International Labour Organisation (http://ilo.org/global/about-the-ilo/lang--en/index.htm) ) have increasingly recognised the importance of continuous professional development of early years staff and their work conditions as determinants of ECEC structural and process quality which, in turn, are linked to children's cognitive and non-cognitive attainment (OECD, 2012a; OECD, 2012b; ILO, 2014). However, whilst a broad consensus exists among researchers and policy-makers on the importance of investing in staff professionalisation in order to increase the quality of educational and care practices in early childhood services, the processes and tools whereby practitioners' development can be promoted remain unexplored in international literature (Sheridan, Pope Edwards, Marvin, \& Knoche, 2009) and there is too little investment in strong systems of continuous professional development in the European Member States (Peeters, Sharmahd, \& Budginaité, 2016).

In the light of the current policy context where accountability for outcomes is increasingly high and resources for professional support are limited because of austerity in many EU countries, policy-makers are progressively relying on research evidence to provide relevant information to orient decision-making processes in the educational field. In this regard, the 'Evidence Informed Policy-making in Education in Europe' (EIPEE) Project's recommendations suggest increasing the use of systematic reviews of research in order to 'ensure complete, relevant, quality assured and accessible research evidence’ (Gough, Tripney, Kenny, \& Buk-Berger, 2011, p. 10). Such research evidence includes not only evaluation studies on which interventions work, but also practice-based research evidence about which interventions could work, for whom and in which contexts (Pawson, Greenhalgh, Harvey,\& Walshe, 2005). It has been argued that determining 'what works' by relying solely on the measurements of pre-defined outcomes may not necessarily provide the most valid form of evidence in the ECEC field (Vandenbroeck, Roets, \& Roose, 2012) in which multiple 
stakeholders are involved in decision-making processes at several levels (policy-makers, local administrators, practitioners, children, families and local communities). It is therefore important to look at both quantitative and qualitative studies.

\section{AIM OF THE RESEARCH}

In 2014 and 2015, researchers of the Centre for Innovations in the Early Years (VBJK), the Thomas Coram Research Unit at the UCL Institute of Education in London and the Public Policy and Management Institute (Lithuania) jointly conducted a systematic literature review (Eurofound, 2015) on the impact of work conditions and continuous professional development of the ECEC workforce on the quality of the services provided and on the outcomes for children. It was commissioned by the European Foundation for the Improvement of Living and Working Conditions (Eurofound) (www.eurofound.europa.eu) to support European decision makers in designing effective ECEC policies in their countries. The overarching aim was to explore links between continuous professional development (CPD), work conditions, staff-child interactions (process quality) and children's learning and socialising experiences and outcomes. More specifically, its objectives were:

1. to investigate whether - and under which conditions - the investment in CPD initiatives and work conditions contribute to the improvement of practitioners'educational and care practices in ECEC settings;

2. to document the effects of CPD activities and work conditions on the everyday interactions between practitioners and children as well as on children's learning and well-being;

3. to identify the features of CPD programmes and work conditions that are found to be more effective in relation to point 1 and 2 .

In order to achieve these objectives, the studies analysed in the systematic review, which were published in several EU languages, included:

1. quantitative studies (RCTs, quasi experimental designs, controlled before and after interventions) examining the impact of CPD on ECEC quality (measured by rating scales), staff-child interaction (assessed through observation scales) and outcomes for children (standardised assessment of cognitive and social abilities);

2. qualitative studies exploring practitioners' views and experiences of continuous professional development as well as reflective accounts on their practices and on children's achievements;

3. mixed method studies, combining quantitative and qualitative elements.

An analysis of the findings emerging from the synthesis of quantitative, qualitative and mixed method studies was then carried out in order to answer the research questions identified for the literature review.

\section{METHODOLOGY AND PROCEDURES}

Systematic reviews of the literature are research projects which aim to map, synthesise and critically evaluate the results of all existing studies within a particular field of study, circumscribed by clear hypotheses or clearly defined research questions (Gough et al., 2012). At every stage of the process, the researchers use standardised procedures that are previously encoded in a research protocol (systematic review protocol). In the case of the review we conducted - and with particular reference to the protocol developed for the review of qualitative literature - , the procedures 
adopted for the systematic analysis of study findings were as follows (Hauari, Lazzari, Cameron, Peeters, Rimantas, \& Siarova, 2014):

1. Selecting criteria: the specific criteria determining which studies should be included in the analysis were jointly elaborated by the research team and referred to: a) date of publication (after 1991), b) geographical location (EU-28 Member States), c) the research design used (exclusively empirical studies), d) the subjects (educational staff and children aged 0-7 attending ECEC services), and e) the type of results reported in the publication (practitioners' perceptions, narrative accounts, case studies analysing good practices, observations and standardised testing, rating scale measurements, etc.);

2. Searching: exhaustive search and reproduction of all relevant information (published studies and 'grey' literature) on the subject under consideration via major international databases such as ASSIA, BEI, Child Data, ERIC, IBSS, PsycInfo, SCOPUS, Sociological Abstracts, SSCI. In addition, for sources in languages other than English, we consulted country experts from the EU-28 Member States who searched national databases or specialised journals. Their involvement allowed for the search and inclusion of studies across all European research traditions and more evidence for this review;

3. Screening: systematic selection on the basis of previously defined inclusion criteria (see point 1) of the studies to be included in the analysis (the screening was carried out in two stages - abstract screening and subsequent full-text screening);

4. Mapping: mapping of existing literature from the analysis of the descriptive characteristics of each of the selected studies (objective research, methodological, selection of participants, characteristics of the CPD programme or work condition studied);

4. Quality Assessment / Data Extraction: the assessment of the methodological quality of each of the selected studies used a grid that was specially structured to determine the degree of soundness with which they were given the perceptions of those involved and the degree of reliability with which the results were presented: for the textual extracts that were relevant for the analysis of the results of the studies we used an additional grid (complementary to the previous one) that allowed us to organise and systematise information from each study in descriptive categories that are typical of qualitative research.

5. Narrative synthesis: the results of the empirical studies which were assessed as sound, accurate and reliable were finally analysed in-depth by grouping significant text extracts in thematic categories and their discussion in narrative form (Harden \& Thomas, 2008).

The use of these procedures ${ }^{2}$ which were elaborated by the research group on the basis of guidelines developed by the EPPI Centre for conducting systematic reviews in the social sciences made it possible to explain step by step the ways in which the study had 'answered' the research questions by means of a rigorous analysis that comprehensively mapped the existing evidence provided by the qualitative and quantitative literature published on this issue in Europe.

The main limitations were scarce primary empirical studies available on the topic and a lack of comparability of the findings. For example, the contexts in which the studies were produced were often historically different in terms of the typology and processes of ECEC provision, making the comparison and generalisation more difficult. Nevertheless, it was possible to bring together the findings through a 'third-level synthesis', allowing for the juxtaposition of the results from quantitative and qualitative studies (Thomas, Harden, Oakley, Oliver, Sutcliffe, Rees, \& Kavanagh Thomas, 2004 


\section{FOCUS OF THIS ARTICLE}

A full description of the methodology and the procedures used (Eurofound, 2015) and an overview of the main results (Eurofound, 2015; Peeters \& Peleman, 2017) are documented elsewhere. Given the ample scope of the systematic review, we will focus on the analysis of qualitative and quantitative study findings investigating the effects of CPD initiatives on the quality of the pedagogical practices of ECEC practitioners. In doing so, we will not only try to provide policyrelevant information on continuous professional development initiatives implemented in the ECEC field, but also offer an explanatory analysis allowing for a contextualisation of the research findings.

In the systematic review, the term 'continuous professional development' was adopted to refer to all planned programmes of learning opportunities for those working in ECEC that were undertaken to complement, update and consolidate the professional knowledge and competence of individuals and teams working in those settings (Hauari et al. 2014).

By focusing on the effects of CPD initiatives on the quality of ECEC services, we are aware that 'quality' is a contested concept: there is no internationally agreed definition in ECEC services (European Commission, 2014). Moreover, 'quality is a relative concept based on values and beliefs, and defining quality should be a dynamic, continuous and democratic process' (European Commission Network on Childcare and Other Measures to Reconcile the Employment and Family Responsibilities, 1996, p.11). In the systematic review, we therefore did not solely focus on quantitative studies that provide data on the impact of CPD initiatives on the quality of ECEC services, as measured through international validated rating scales. A very import additional element was the views of practitioners in order to address the political, ethical and thus relational dimension of ECEC practices. In this sense, we align with the 'Contesting Early Childhood' movement and its criticism of standardised and unquestioning views of 'quality' as driven by attaining high returns on investment and reducing social problems (Moss, Dahlberg, Olssen, \& Vandenbroeck, 2016), thus narrowing ECEC down to a mere technical issue. This neglects the high potentiality of the democratic value of ECEC for social justice and equity (Moss, 2011). Hence, the relevant research synthesised in this review includes both quantitative and qualitative studies. In the latter, the 'effectiveness' of continuous professional development initiatives is evaluated in relation to practitioners' views and understandings. Moreover, by also looking for research findings published in languages other than English, we aimed to include 'alternative narratives' that shed a different light, away from the dominant discourse towards the story of 'democracy, experimentation and potentiality' (Moss et al., 2016, p.5).

\section{GEOGRAPHICAL DISTRIBUTION AND CHARACTERISTICS OF THE STUDIES}

As a result of the search and screening procedures described above, 44 studies were included in the in-depth systematic literature review of the Eurofound study (2015). 30 were defined as qualitative/views studies, four of which were originally mixed-method studies. However, as a result of the quality appraisal, only the qualitative research findings of these studies were included in the review. 12 were impact studies and 2 were defined as mixed-method studies, of which both the qualitative and quantitative research findings were included in the review. Of those 44 studies, 39 focused on CPD, 4 on work conditions and 1 on both. Of all the studies on CPD (including the one study that focused on both CPD and working conditions), 29 were defined as qualitative studies, 10 as quantitative and 1 as a mixed method study. Figure 1 explains how we arrived at these figures. 
FIGURE 1. Flow diagram of the systematic literature review

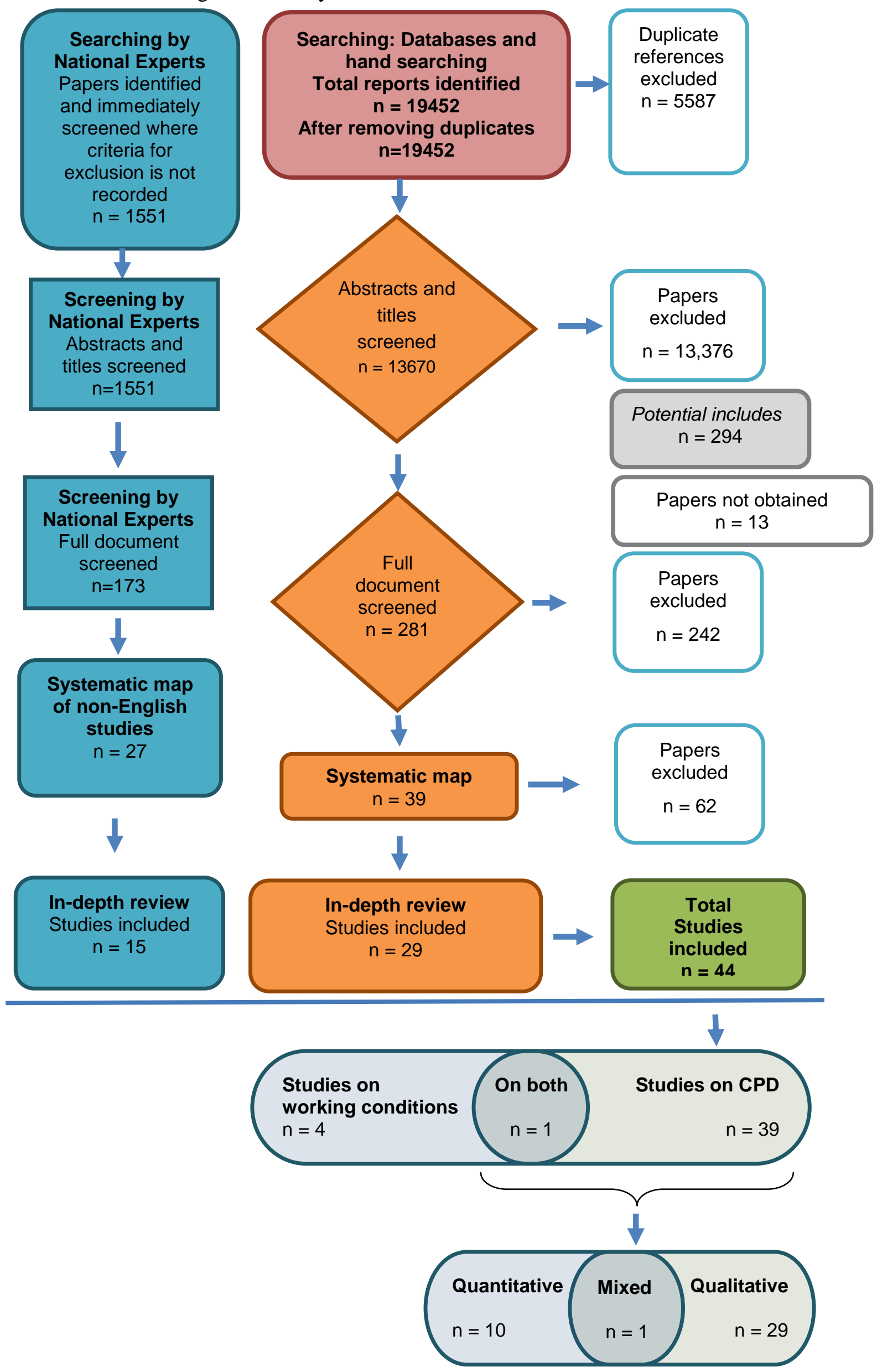


30 qualitative studies $^{3}$ (Eurofound, 2015) reported on the link between CPD and ECEC quality, the results of which are discussed in this article. Seven were from the UK (Ang, 2012; Aubrey, Ghent, \& Kanira, 2012; Blenkin \& Hutchin, 1998; Jopling, Whitmarsh, \& Hadfield, 2013; Menmuir \& Christie, 1999; Potter \& Hodgson, 2007; Wood \& Bennett,2000), five were from Portugal (Cardoso, 2012; Craveiro, 2007; Leal, 2011; Lino, 2005; Peixoto, 2007; Oliveira-Formosinho \& Araújo, 2011), five were from Ireland (Bleach, 2013; Hayes, Siraj-Blatchford, \& Keegan, 2013; McMillan, Walsh, Gray, Hanna, Carville, \& McCracken, 2012; Share, Kerrins, \& Greene, 2011; SQW, 2012) and a further five from Sweden (Asplund Carlsson, Pramling, \& Pramling Samuelsson, 2008; Johansson, Sandberg, \& Vuorinen, 2007; Rönnerman, 2003, 2008; Sheridan et al., 2013). Two were from Belgium (Peeters, 1993; Peeters \& Vandenbroeck, 2011). The remaining five were carried out in Croatia (Vujičić, 2008), Germany (Richter, 2012), Italy (Picchio, Giovannini, Mayer, \& Musatti, 2012), The Netherlands (Van Keulen, 2010) and Slovenia (Vonta, Rutar, \& Istenič Starčič, 2007).

Of these 30 qualitative studies, 12 were participative, using a combination of interviews, focus groups, questionnaires, reflective journals, participative observation and recordings of audio and video data related to pedagogical practices. Fifteen adopted an action-research approach in order to involve practitioners in the process of data collection and data analysis: findings were discussed and constructed with practitioners, mostly through collective planning and reporting sessions. The remaining three studies were descriptive case studies reporting on the effects of CPD initiatives on the knowledge and understandings of practitioners, as well as on pedagogical practice as observed by the researchers (Craveiro, 2007; Menmuir \& Christie, 1999; Oliveira-Formosinho \& Araújo, 2011).

Of the 14 impact studies (Eurofound, 2015), three focused on the impact of CPD on ECEC quality. The first was from Ireland (Hayes et al., 2013) and its mixed-method study is included under both qualitative and quantitative studies. It reported on the results of a 'cluster randomised trial' which is an experimental method whereby social units or clusters (Early Years services) are randomly allocated to intervention or control groups. The second study was from Sweden (Sheridan, 2001) and adopted an evaluation design with before and after measurement involving an experimental and a control group in order to assess the effectiveness of CPD interventions. The last study was from Belgium (Vandenbroeck, 2008, 2014) and used a longitudinal design involving a before and after measurement to evaluate the impact of an intervention combining training and policy measures.

Since this article focuses on the link between CPD and ECEC quality, 32 studies were selected, of which 29 were defined as views studies, two as impact studies and one as a mixed method study. Ten were published in another language than English: five in Portuguese (Cardoso, 2012; Craveiro, 2007; Leal, 2011; Lino, 2005; Peixoto, 2007), two in Swedish (Asplund Carlsson et al., 2008; Rönnerman, 2008) and the remaining three in Dutch (Peeters, 1993), German (Richter, 2012) and Slovenian (Vonta et al., 2007). We involved country experts in data extraction that was relevant for the in-depth review.

\section{CHARACTERISTICS OF THE CPD INTERVENTIONS}

All studies reported findings on the effects of training interventions that were integrated in ECEC practices through a combination of training sessions and follow-up activities in the settings. In particular, 22 views studies and all three impact studies investigated integrated programmes in which training sessions were accompanied by coaching or supervision, thus providing practitioners with the opportunity to exchange reflections and receive feedback on practice. The many qualitative studies exploring CPD programmes accompanied by follow-up activities such as coaching, supervision and collective reflection are partly due to the fact that in action-research designs revision and transformation of practices are integral parts of the research process which is carried 
out as a joint activity involving both practitioners and researchers. Hence, in this kind of research, the boundaries between the processes of CPD implementation and research investigation are less evident than in impact studies. Furthermore, most CPD initiatives reported in these views studies included in the in-depth synthesis refer to long-term programmes lasting from six months to one year (11 studies) or longer (13 studies). However, in six, the length of the CPD programme was not clearly specified. All three impact studies investigated the impact of long-term interventions lasting from one to two years.

\section{RESULTS}

With regard to ECEC quality, most studies indicated that the main benefits of continuous professional development for practitioners concerned practitioner capacity: greater pedagogical awareness, knowledge and sense of agency; and pedagogical competence: the acquisition of new methodological skills linked to the improvement of practices in ECEC settings. Concerning the latter, two main areas of improvement were identified: a) the development, implementation and ongoing revision of the curriculum, and b) collegial (team) work, inter-professional collaboration and parents' engagement in decision-making processes.

\subsection{Practitioners' knowledge, understanding and sense of agency}

Effects of CPD initiatives on practitioners' knowledge, understanding and sense of agency were found at different levels: greater competence and sense of confidence, deeper reflectivity on practice - which sometimes implied deconstruction and re-conceptualisation of their professional role -, a change in perspective on how children learn and make sense of experiences, a changed attitude towards parents and better planning and evaluation.

An overarching finding was that CPD improved participants' sense of confidence as practitioners and leaders in ECEC services (Ang, 2012; SQW 2012; Hayes et al., 2013; Sheridan et al., 2013; Richter, 2012). Through the demands of the CPD programmes and reflective tools used, practitioners increased their pedagogical awareness and professional understandings which, in turn, allowed them to strengthen their capacities and address areas for improvement (Ang, 2012; Menmuir \& Christie, 1999; Hayes, et al., 2013; Rönnerman, 2003; Vonta et al., 2007). For example Sheridan et al's. (2013) study of the effects of 'systematic quality work' in ECEC services in Iceland, Sweden and Norway reported that the knowledge gained by teachers through the analysis of pedagogical documentation and the systematic evaluation of educational practice made them more aware of their competence and of the quality of their work. Such initiatives foster teachers' abilities to take into account multiple theoretical perspectives and to reflect critically on educational policies and curriculum intentions.

A crucial aspect of CPD provision in influencing practitioners' greater pedagogical awareness and deeper reflectivity is the active involvement of participants in transformative processes to improve educational practices in ECEC settings. By engaging in research-based enquiry, practitioners can critically explore the link between theory and practice in their everyday work and this enables them to identify and address the gaps between intended pedagogical principles and enacted practices (Wood \& Bennett, 2000; Johansson et al., 2007; Lino, 2005). Furthermore, involving them in a process of change where they can be 'actors of change' not only impacts on their practical knowledge, but also on their professional attitudes and understandings (Peeters \& Vandenbroeck, 2011; Rönnerman, 2003, 2008; Blenkin \& Hutchin, 1998). One of the most salient effects of professional development, especially when accompanied by guidance, is the empowerment of practitioners to question taken-for-granted assumptions that underlie their practices. Rönnerman (2003, p. 17) found that 'by letting the teachers find their own questions and by letting the question guide them in searching for new knowledge about their practices, the teachers retain authority over their improvement of practices' and that this, in turn, strengthens their 
professional competences. Several studies also found that taking part in CPD led practitioners to reconceptualise their role as educators (Blenkin \& Hutchin, 1998; McMillan et al., 2012; Potter \& Hodgson, 2007; Rönnerman, 2003; Sheridan et al., 2013; Vujičić, 2008; Wood \& Bennett, 2000).

In parallel to rethinking their own role, practitioners also began to reconceptualise children as protagonists of their own learning (Cardoso, 2012; Sheridan et al., 2013). In this sense, the study by Cardoso (2012) describing the effects of a CPD programme carried out in a community ECEC centre through an action-research process highlighted how practitioners changed their views of the children: from spectators they became participating children. This implied a change in the organisation of the educational environment (space and time) within the setting. The way in which they planned and assessed practice also changed, reflecting a shift towards an approach focused on listening to children. The role of play was reconceptualised from something that children 'naturally' did (without the involvement of adults) towards something that gave them the possibility to intervene directly in the everyday pedagogy and support their possibilities to invent and find out about the world (Cardoso, 2012).

Moreover, we found that engaging in practice-based research and professional development activities in highly socio-culturally diverse ECEC contexts could lead practitioners not only to refocus on children's needs and potential, but also to reconceptualise their perceived role of parental involvement. The Portuguese study evaluating the effects of a praxeological research ${ }^{3} \mathrm{CPD}$ intervention reported that practitioners started to view 'listening to children as an important dimension that supported activity and projects' and 'listening to parents as a strategy to develop daily life in the classroom in a pluralist way' (Oliveira-Formosinho \& Araújo, 2011, p. 8). Similarly, findings from participatory action-research carried out in Flanders (Peeters \& Vandenbroeck, 2011, p. 67) highlighted that practitioners became progressively 'more interested in the way parents educate their young children at home and in questioning how the childcare centre could take on some of the practices of the parents'. Through these processes, children were increasingly considered as active citizens who could decide upon important aspects of the daily life in the childcare centre.

An analysis of practitioner perspectives showed that the adoption of particular CPD tools had contributed to improving the quality of their practice. For example, tools that sustained practitioners' reflection were identified in several studies as a key element in a cycle that usually included observation, documentation, action and review. Ang's (2012) study highlighted the use of 'journals' as a specific aspect of the training which was found particularly useful and on which centre leaders continued to draw in their work with partner agencies as a tool that facilitated interprofessional work. Similarly, the 'narrative dossier' used as a CPD tool in the municipal day-care centre of Pistoia (Italy) contributed to the enhancement of practitioners' competence in analysing and improving the quality of children's everyday experiences in early childhood settings by sharing observations with colleagues and parents (Picchio et al., 2012). Teachers' statements confirmed that the use of written documentation of children's experiences within the setting (weekly and monthly accounts) allowed them 'to grasp more fully the aspects of continuity and change' underlying the ongoing development of learning interactions occurring in the centre and 'to re-direct educational practices' more responsively (Picchio et al., 2012, p. 164).

In Sheridan's (2001) impact study, the use of a specific tool called a 'competence development intervention' was evaluated in 20 Swedish preschool units. This intervention adopted the Early Childhood Environment Rating Scale (ECERS) (http://ers.fpg.unc.edu/early-childhood$\underline{\text { environment-rating-scale-ecers-r) }}$ as a tool to reflect on and improve practices. The 'Model of Competence Development' evaluated in the study consisted of a combination of lectures, reflection in groups and pedagogical guidance (ECERS self-evaluation, reflective diaries and analysis of 
video-documentation). The evaluation found that the development work led to better quality in eight of the nine preschool units in the intervention group.

\subsection{Curriculum development, implementation and innovation}

The synthesis of qualitative study findings revealed that context-based CPD initiatives combining pedagogy and supervision 'on the job' were more successful in enhancing the quality of ECEC settings than traditional 'one off' training courses, or where learning is conceived as an individual process based on acquiring theoretical foundations and discrete skills with no integration in the specific operational contexts. More specifically, the analysis revealed that the systematic use of methodological tools such as video-observation and documentation of children's experiences, action plans, diaries, portfolios and analytical grids supported educational practices that were more responsive to children's needs, potentialities and learning strategies. Potter \& Hodgson (2007) identified the fact that practitioners began to engage systematically in a process of critically reflecting on their daily practice which was greatly facilitated by the use of video clips and workbased supervision as the key-benefit of a video-cued training on adult-child interactions. In the studies examined, videotapes were also used to observe and/or document children-initiated activities (Blenkin \& Hutchin, 1998; Sheridan et al., 2013).

In this sense, the main effect of action-research driven CPD programmes that make use of such tools is to elicit practitioners' intentionality that leads to a more meaningful planning, implementation and evaluation of educational initiatives based on children's needs rather than on pre-determined choices made by adults (Bleach, 2013). For example, Oliveira-Formosinho \& Araújo (2011, p. 8) reported that: 'the development of systematic observations that identified children's interest and motivations allowed for educational planning that departed from children and not from an abstract child'. In this case, educators' awareness of the importance of listening to children and their enhanced competence in observation strategies allowed them to enact educational practices that were more supportive of children's agency in experiential learning situations.

Along this line, the elaboration of more responsive educational strategies to enhance children's learning were highlighted as one of the main effects of CPD in 15 studies (Asplund Carlsson et al., 2008; Blenkin \& Hutchin, 1998; Jopling et al., 2013; Leal, 2011; McMillan et al., 2012; Picchio et al., 2012; Rönnerman, 2003,2008; Share et al, 2011; SWQ, 2012; Vujičić, 2008; Hayes, et al., 2013; Johansson, 2007; Richter, 2012; Cardoso, 2012). As exemplified in the actionresearch studies conducted by Rönnerman's (2003, 2008), following the CPD intervention, preschool teachers deliberately shifted their didactic approach by trying to find out what the children knew before planning an activity. Daily work was no longer pre-planned only, but was also open to listening to children's needs and ideas that arose during the day. Teachers asked the children and used the information to plan new themes, giving children an active role in the planning of, for example, thematic work. One teacher reflected on the change in the practice in her setting in these terms: 'You have been more sensitive about the children's' interests. Take their competence as a departure and spin on to it. You do not stop and stay within your frames anymore; you go a step further and find out things you might not have planned. You don't have to stick with your plans, if the child comes up with questions you find out the answers together with him/her. (Rönnerman, 2003, p.16)

\subsection{Collaborative practices}

As it might be expected from CPD initiatives that are workplace-based and focused on practitioner learning in dialogue with colleagues, a clear area of impact was on collegiality or teamwork, working with parents and inter-professional collaboration. 
The positive effects of CPD initiatives on practitioners' teamwork were reported in 13 studies (Bleach, 2013; Craveiro, 2007; Hayes, et al., 2013; McMillan et al., 2012; Picchio et al., 2012; Rönnerman 2003, 2008; Share et al., 2011; SQW, 2012; Vonta et al., 2007; Vujičić, 2008; Van Keulen 2010; Wood \& Bennett, 2000). For example, Rönnerman (2003, p. 17) noted that keeping work teams together during CPD training had 'strengthened them as a group', and gave them a common 'language to explain things'. Through the work in teams carried out during CPD activities, practitioners gained the confidence to both 'give away our best ideas instead of keeping them to ourselves' (as one pedagogue said) and to voice their opinions in staff meetings more readily (Rönnerman, 2003, p. 17). One particular method of strengthening team work that was considered valuable by Van Keulen (2010) was paired work with colleagues as 'critical friends' which enabled each pair to reflect, carry out assignments and give each other feedback on the learning process. Van Keulen (2010) reported that the technique of asking critical questions deployed during the action research CPD encouraged practitioners, the team and the organisation as a whole to phrase questions about practice: 'what do I think', 'why do I act the way I do', 'who benefits', 'how does the team deal with parents that do not live up to our ideals', and 'with which parents has the organization had insufficient or no contact over the past period, and how come?' This was considered productive at both a personal and at a team level (Van Keulen, 2010, p. 109). This study concluded that in The Netherlands giving sufficient attention to developing teamwork discussion and exchange was key for creating sustainable change in ECEC services. Research findings, however, also shed light on the difficulties of sustaining changes in teamwork at institutional level, especially in settings where not all practitioners had participated in the CPD (Picchio et al., 2012) and where the amount of non-contact time granted to practitioners for collegial meeting was inadequate to sustain collective reflection (SQW, 2012).

Seven studies reported that CPD initiatives had a positive impact on working with parents (Share et al., 2011; SQW, 2012; Vujičić, 2008; Rönnerman, 2003; Van Keulen, 2010; Peeters, 1993; Hayes et al., 2013). For example, the study conducted by Share et al. (2011) found that practitioners' participation in the 'Pen Green Training on Involving Parents in their Children Learning' led to a more intensive and more confident dialogue with parents, a more welcoming approach, 'generally fostering a spirit of openness with parents' (Share et al., 2011, p. 58). Staff training had also helped parents to trust the practitioners and to give them confidence to 'ask questions about their child's learning' (Share et al., 2011, p. 89). Conversely, dialogue with trained practitioners gave the parents confidence in their own parenting practices and new knowledge about how to name and value what the children were doing (Share et al., 2011, p. 89). Rönnerman (2003) and Van Keulen (2010) both reported that increased practitioner confidence in working with parents led to parents' greater respect for staff. Vujičić (2008) found a higher level of parental engagement as a result of action research CPD, particularly in practical support, such as 'bringing the material, sawing the cupboard and painting the walls' (Vujičić, 2008, np). Similarly, Peeters (1993) highlighted that at the end of the quality improvement process there was a noticeable increase in parental participation in childcare centres. Get-together events started to take place regularly and parent evenings began to be organised around a set theme (Peeters, 1993). The mixed-method evaluation study conducted by Hayes et al. (2013) also reported greater trust and involvement of parents in those services where CPD interventions were carried out: these settings displayed fewer instances of very low child attendance when compared to control services (Hayes et al., 2013).

With regard to parents, the study by Vandenbroeck et al. (2008 and 2014) sheds light on structural quality aspects such as availability, access and enrolment. Over a 5-year period, new municipal policies were developed with financial incentives to enhance the accessibility of child care to children from low-income families, single parent families and ethnic minority families. In addition, a CPD programme was set up with monthly training sessions with a trainer and coaching activities carried out within inter-professional exchanges with social and welfare workers. The findings showed that centre directors' awareness of social priority criteria changed, resulting in a 
significant increase in the enrolment of children from single-parent and ethnic minority families whereas no significant effects could be found in the enrolment of children from low-income families. In addition, inequality in relation to the availability of childcare places remained. The results support the hypothesis that policy measures, combined with training and ongoing support, can influence inequalities in enrolment rates.

Finally, three studies showed that the positive effects of CPD initiatives on collaborative practices could extend beyond the boundaries of ECEC institutions, creating the conditions for fostering inter-professional learning and networking across social and health services operating in neighbourhoods (Ang, 2012; Bleach, 2013; SQW, 2012). For example, Ang's (2012) evaluation of a CPD programme on 'leadership in children's centres' found that the training led to more effective partnerships with colleagues from different professional backgrounds. This had in part come about by establishing a centre's vision and partly by the realisation that a more integrated strategy was needed in order to make a difference for children and families living in the local community. In this perspective, activating multi-disciplinary training became the necessary precondition for co-creating integrated practices at local levels (Ang, 2012). In other cases, where participatory training initiatives brought together practitioners from a number of settings, networking and dialogue across settings helped to disseminate good practices and provided reflective opportunities through peer exchange (Bleach, 2013; SQW, 2012).

\section{CONCLUSIONS}

In the light of the analysis of research findings synthesised so far, it can be concluded that CPD interventions that are integrated in the ECEC centre's practice with a feedback component are the most effective in terms of lasting impact on practitioners' learning, development and the quality of their practices. Long-term CPD interventions that are integrated in practice, such as pedagogical guidance and coaching in reflection groups, produce positive impacts in very different contexts. The impact appears to hold both in countries where there is well-established ECEC provision and high staff qualification requirements and in those with a low level of qualification entry requirements for ECEC practice.

The findings of the reviewed studies showed that taking part in CPD activities increased practitioners' pedagogical awareness and professional understandings and deepened capacity for and practice of reflectivity, enabling them to strengthen their capabilities and address areas for improvement in their everyday work in ECEC settings. Several studies found that by taking part in participative CPD, practitioners reconceptualised their role as educators: they began to see children as protagonists of their own learning. Research findings also stressed that participatory and reflective CPD initiatives carried out in highly socio-culturally diverse ECEC contexts could lead practitioners to reconsider the role of parental involvement by provoking interest in the way parents educated their children at home and by questioning how these parenting practices could be adopted and included in the ECEC centres.

The elaboration of more responsive educational strategies for enhancing children's learning - as well as of more coherent ways to develop, implement and evaluate the curriculum was highlighted as one of the main effects of CPD on practitioners' practices.

The reviewed studies also indicated that workplace-based CPD had a wider effect on collegiality, team work and inter-professional collaboration, as it contributes to strengthening the team of educators as a group by valuing their diverse competences and expertise.

Finally, our review also made it possible to draw indications of what might be critical success factors in determining a positive impact of CPD programmes on the improvement of pedagogical practices - and hence - on the quality of ECEC settings. First, CPD provision must be 
embedded in a coherent pedagogical framework or curriculum that builds upon research and addresses local needs. Secondly, CPD initiatives should be grounded in an active involvement of practitioners in the transformative process for the improvement of educational practices within ECEC settings. Third, CPD needs to be focused on practitioners learning in practice, in dialogue with colleagues and parents and to maximise effectiveness of CPD practice a mentor or coach should be available during ECEC staff child-free hours.

Furthermore, it emerged from the systematic literature review that a dialogic engagement of researchers and ECEC professional in practice-based enquiry or action-research projects could sustain a joint reflection on the links between theory and practice. This might drive transformational change in the field of ECEC by allowing practitioners to critically explore their everyday work in order to improve their pedagogy and academics to draw attention to those issues that are relevant to the actors in the field (professionals, children and families). The cycle of observing, planning, acting, documenting and reflecting that is used in practice-based enquiry and action research, can provide the structure to implement curricula that are more focused on children's learning potentialities rather than on pre-determined outcomes. In this sense, participatory and practicebased research studies could contribute not only to raise the quality of early childhood services through the dissemination and exchange of good practice, but also to raise the status of ECEC by wide spreading a local 'culture of childhood' and supporting policy-advocacy.

\section{NOTES}

${ }^{1}$ A generalised and equal access to high quality ECEC is key to the achievement of two headline targets of EU 2020 strategy: 1) reducing the rates of early school leaving below 10\% and 2) fighting poverty and social exclusion (at least 20 million fewer people in or at risk of poverty and social exclusion). http://ec.europa.eu/europe2020/europe-2020-in-a-nutshell/targets/index_en.htm

${ }^{2}$ The complete description of the methodology and steps followed during the systematic review is presented in Peeters, J.; Cameron, C.; Lazzari, A.; Peleman, B.; Budginaite, I.; Hauari, H.; Siarova, H. (2014). Impact of continuous professional development and working conditions of early childhood education and care practitioners on quality, staff-child interactions and children's outcomes: A systematic synthesis of research evidence. Gent: VBJK.

${ }^{3}$ A research paradigm in which a deep reflection on power and ethics is put at the foreground of the participatory relationship with collaborators. It intends for social and political transformation. (Oliveira-Formosinho \& Formosinho, 2012).

\section{REFERENCES}

Ang, L. (2012). Leading and managing in the early years: A study of the impact of a NCSL programme on children centres leaders' perceptions of leadership and practice. Educational Management Administration \& Leadership, 40, 289-304.

Asplund Carlsson, M., Pramling, N., \& Pramling Samuelsson I. (2008). Från görande till lärande och förstålse. En stuie av av lärares lärande inom musik. Nordisk Barnehageforskning, 1, 41-51.

Aubrey, C. Ghent, K. \& Kanira, E. (2012). Enhancing thinking skills in early childhood. International Journal of Early Years Education, 20, 332-348.

Bennett, J., Gordon, J., \& Edelmann, J. (2012). ECEC in promoting educational attainment including social development of children from disadvantaged backgrounds and in fostering social inclusion. European Commission: Directorate General Education and Culture.

Bennett, J. \& Moss, P. (2011). Working for inclusion: How early childhood education and care 
(ECEC) and its workforce can help Europe's youngest citizens. Edinburgh: Children in Scotland.

Bleach, J. (2013). Using action research to support quality early years practice. European Early Childhood Education Research Journal, 21, 370-379.

Blenkin, G. \& Hutchin, V. (1998). Action research, child observations and professional development: some evidence from a research project. Early Years: An International Research Journal, 19, 62-75.

Cardoso, M. G. (2012). Criando contextos de qualidade em creche: ludicidade e aprendizagem. Tese de doutoramento em Estudos da Criança. Universidade do Minho.

Craveiro, M. C. (2007). Formação em contexto: um estudo de caso no âmbito da pedagogia da infância. Tese de doutoramento em Estudos da Criança. Universidade do Minho.

European Commission (2013). Barcelona objectives: The development of childcare facilities for young children in Europe with a view to sustainable and inclusive growth. Brussels.

European Commission. (2011). Early Childhood Education and Care: Providing all our children with the best start for the world of tomorrow (COM. 66). Brussels.

European Commission (2014). Study on the effective use of early childhood education and care $(E C E C)$ in preventing early school leaving (ESL). Final report prepared for the EC by PPMI.

Council of the European Union. (2011). Council conclusions on early childhood education and care: providing all our children with the best start for the world of tomorrow. (2011/C 175/03).

EACEA P9 Eurydice. (2009). Key data on education in Europe 2009. Eurydice Network. (DOI: 10.2797/1715).

Eurofound. (2012). Third European Quality of Life Survey - Quality of life in Europe: Impacts of the crisis. Luxembourg: Publications Office of the European Union.

Eurofound. (2015) Working conditions, training of early childhood care workers and quality of services. A systematic review. Luxembourg: Publications Office of the European Union.

European Commission Network on Childcare and Other Measures to Reconcile the Employment and Family Responsibilities. (1996). Quality targets in services for young children. Proposal for a ten year action programme. Luxembourg: European Commission.

Eurydice (2009). Early Childhood Education and Care in Europe: Tackling social and cultural inequalities. Brussels: Education, Audiovisual and Culture Executive Agency.

Gough, D., Tripney, J., Kenny, C., \& Buk-Berger, E. (2011). Evidence informed policy-making in education in Europe. EIPEE Final Project Report. London: EPPI-Centre.

Gough, D., Oliver, S., \& Thomas, J. (2012). An introduction to systematic reviews. London: Sage Publications.

Hayes, N., Siraj-Blatchford, I., \& Keegan, S. (2013). Evaluation of the Early Years Programme: Child Development Initiative (Ireland). Dublin: CDI.

Hauari, H., Lazzari, A., Cameron, C., Peeters, J., Rimantas, D., \& Siarova, H. (2014). Impact of training and working conditions of early childhood education and care practitioners on children's outcomes. Protocol for systematic review. London: University of London: Institute of Education.

International Labour Organisation (2014). Policy guidelines on the promotion of decent working conditions for early childhood education personnel. Geneva.

Johansson, I., Sandberg, A., \& Vuorinen, T. (2007). Practitioner- oriented research as a tool for professional development. European Early Childhood Education Research Journal, 15,151166

Jopling, M., Whitmarsh, J., \& Hadfield, M. (2013). The challenges of evaluation: Assessing early talk's impact on speech language and communication practice in children's centres. International Journal of Early Years Education, 21, 70-84.

Leal, R. A. (2011). Formando o cidadão desde o jardim-de-infância: o contributo das práticas de avaliação das aprendizagens dos educadores de infância em colaboração com a família. Universidade de Aveiro: Departamento de Educação. 
Lino, D. (2005). Da formação escolar à formação em contexto: um percurso de inovação para a reconstrução da pedagogia da infância. Tese de doutoramento em Estudos da Criança: Universidade do Minho.

McMillan, D., Walsh, G., Gray, C., Hanna, K., Carville, S., \& McCracken, O. (2012). Changing mindsets: The benefits of implementing a professional development model in early childhood settings in Ireland. Professional Development in Education, 38, 395-410.

Menmuir, J. \& Christie, D. (1999). Encouraging professional reflection in early education. International Journal of Early Years Education, 7, 61-75.

Moss, P. (2011). Democracy as first practice in early childhood education and care. In J. Bennett., R. Tremblay, M, Boivin, \&. R, Peters. (Eds.), Encyclopedia on early childhood development: 1-7 [online]. Montreal, Quebec: Centre of Excellence for Early Childhood Development and Strategic Knowledge Cluster on Early Child Development.

Moss, P., Dahlberg, G., Olssen, L.M., \& Vandenbroeck, M. (2016). Why contest early childhood? Essay for the 'Contesting Early Childhood' Series. Routledge. Retrieved from: www.book2look.com/book/CGQqJCANOX?utm_source=Routledge\&utm_medium=cms\&u tm_campaign $=160701429$

NESSE. (2009). Early childhood education and care. Key lessons from research for policymakers. Retrieved from: http://ec.europa.eu/education/news/news1697_en.htm.

Oberhuemer, P. (2012). Fort- und Weiterbildung frühpädagogischer Fachkräfte im europäischen Vergleich. Munich: Deutsches Jugendinstitut.

Oliveira-Formosinho, J. \& Araújo, S. (2011). Early education for diversity: starting from birth. European Early Childhood Education Research Journal, 19, 223-235.

Oliveira Formosinho, J. \& Formosinho, J. (2012). Praxeological research in early childhood: a contribution to a social science of the social. European Early Childhood Education Research Journal, 20, 471-476, DOI: 10.1080/1350293X.2012.73770

OECD (2006) Starting strong II. Early childhood education and care. Paris: OECD.

OECD (2012). Research brief: Qualifications, education and professional development matters. Paris: OECD.

OECD (2012). Research brief: Working conditions matter. Paris: OECD.

Pawson, R. Greenhalgh, T. Harvey, G., \& Walshe, K. (2005). Realist review-a new method of systematic review designed for complex policy interventions. Journal of health services research and policy, 10 (suppl. 1), 21-34.

Peeters, J. (1993) Kwaliteitsverbeteringen in de kinderdagverblijven met steun van de Bernard van Leer Foundation. In: J. Peeters \& M. Vandenbroeck (Eds.), Werken aan een betere kinderopvang. Rapport over dertien jaar onderzoek en vorming. Gent: Universiteit Gent, VBJK.

Peeters, J. \& Peleman, B. (2017 Forthcoming). The competent system at the intersection of research, policymaking and practice. In: L, Miller. C, Cameron. C, Dalli., \& N, Barbour. (Eds.), The SAGE handbook of early childhood policy. London: Sage.

Peeters, J. \& Vandenbroeck, M. (2011). Childcare practitioners and the process of professionalization. In: L. Miller \& C. Cable (Eds.), Professionalization and management in the early years. London: Sage.

Peeters, J., Sharmahd, N., \& Budginaite I. (2016). Professionalisation of childcare assistants in Early Childhood Education and Care (ECEC): Pathways towards qualification. NESET II report, Luxembourg: Publications Office of the European Union. doi: 10.2766/898530

Peixoto, A. (2007). As ciências físicas e as actividades laboratoriais na educação pré-escolar: Diagnóstico e avaliação do impacto de um programa de formação de educadores de infância. Tese de doutoramento em Educação. Braga: Universidade do Minho.

Picchio, M., Giovannini, D., Mayer, S., \& Musatti, T. (2012). Documentation and analysis of children's experience: An ongoing collegial activity for early childhood professionals. Early Years: An International Research Journal, 32, 159-170. 
Potter, C. \& Hodgson, S. (2007). Nursery nurses reflect: Sure Start training to enhance adult child interaction. Reflective Practice, 8, 497-509.

Richter, K. (2012). Naturwissenschaftliche Förderkompetenz von Elementarpädagogen. Eine quantitative und qualitative Untersuchung der Kompetenzentwicklung von Elementarpädagogen im Rahmen einer Fortbildungsmaßnahme zur Förderung der naturwissenschaftlichen Bildung in Kindertagesstätten. Göttingen.

Rönnerman, K. (2003). Action research: educational tools and the improvement of practice. Educational Action Research, 11, 9-21.

Rönnerman, K. (2008). Medvetet Kvalitetsarbete. En uppföljning av kursen Q i förskolan och dess inverkan på förskollärares handlingar i praktiken. Göteborg: Göteborgs Universitet, Institutionen för pedagogic och didaktik.

Share, M., Kerrins, L., \& Greene, S. (2011). Developing early years professionalism. The evaluation of the Early Learning Initiative's professional development programme for community childcare settings in the Dublin Docklands. Dublin.

Sheridan, S. (2001). Quality evaluation and quality enhancement in preschool: A model of competence development. Early Child Development and Care, 166, 7-27.

Sheridan, S., Pope Edwards, C., Marvin, C.A., \& Knoche, L. (2009). Professional development in early childhood programs: process issues and research needs. Early Education and Development, 20, 377-41.

Sheridan, S., Willams, P., \& Sandberg, A. (2013). Systematic quality-work in preschool. International Journal of Early Childhood, 45, 123-150.

*SQW (2012) Evaluation of the 3,4,5 learning years services Youngballymun (Ireland). Dublin: Youngballymun.

Thomas, J., Harden, A., Oakley, A., Oliver, S., Sutcliffe, K., Rees, R., \& Kavanagh, J. (2004). Integrating qualitative research with trials in systematic reviews. BMJ: British Medical Journal, 328 (7446), 1010 - 1012.

Urban, M., Vandenbroeck, M., Peeters, J., Lazzari, A., \& Van Laere, K. (2011). CoRe: Competence requirements in Early Childhood Education and Care. European Commission: DG Education and Culture.

Van Keulen, A. (2010). The early childhood educator in a critical learning community: Towards sustainable change. Contemporary Issues in Early Childhood, 11, 106-112.

Vandenbroeck, M., De Visscher, S., Van Nuffel, K., \& Ferla, J. (2008). Mothers' search for infant child care: The dynamic relationship between availability and desirability in a continental European welfare state. Early Childhood Research Quarterly; 23, 245-258

Vandenbroeck, M., Geens, N., \& Berten, H. (2014). The impact of policy measures and coaching on the availability and accessibility of early child care: a longitudinal study. International Journal of Social Welfare; 23, 69-79.

Vandenbroeck, M., Roets, G., \& Roose, R. (2012). Why the evidence-based paradigm in early childhood education and care is anything but evident. European Early Childhood Education Research Journal, 20, 537-552.

Vonta, T., Rutar, S., Istenič Starčič, A. in Borota, B. (2007). Mentorstvo v profesionalnem razvoju učitelja in vzgojitelja. Koper: Univerza na Primorskem, Pedagoška fakulteta.

Vujičić, L. (2008). Research and Improvement of One's own Practice - Way to development of teachers'/preschool teachers' practical competence. In I. Žogla (Ed.), Teacher of the 21st century: Quality education for quality teaching. Riga: University of Latvia Press.

Wood, E. \& Bennett, N. (2000). Changing theories, changing practice: Exploring early childhood teachers' professional learning. Teaching and Teacher Education, 16, 635-647. 